\title{
RIVALIDADES EN LAS REDES DE PODER DE MANILA: EL GOLPE CONTRA EL GOBERNADOR DIEGO DE SALCEDO ${ }^{1}$
}

\author{
Rivalries Among Manilas's Networks of Power: Blow Against the Governor Diego de Salcedo
}

\author{
Antoni Picazo Muntaner \\ Universitat de les Illes Balears \\ a.picazo@uib.es
}

Fecha de recepción: 8-VII-2012

Fecha de aceptación: 16-X-2012

\begin{abstract}
Resumen: En la segunda mitad del siglo XVII Filipinas vivió un inusitado golpe de mano contra su gobernador y capitán general Diego de Salcedo, el cual fue detenido por la Inquisición de las islas y procesado. Proceso que fue el final de una confrontación como nunca se había vivido entre diferentes redes de poder y que acabó con la intervención de la Corte y la condena unánime de todos los participantes en aquellos acontecimientos.
\end{abstract}

Palabras clave: Diego de Salcedo, Filipinas, redes de poder, golpe.

Авsтract: In the second half of the seventeenth century lived an unusual Philippines blow against the Governor and Captain-General Diego de Salcedo, who was arrested by the Inquisition of the islands and processed. Process that was the end of a confrontation as never lived among different networks of power and ended with the intervention of the Court and the unanimous condemnation of all participants in those events.

Keywords: Diego de Salcedo, Philippines, power networks, blow.

1 Este artículo forma parte del proyecto de investigación financiado por el Ministerio de Innovación y Ciencia no. HAR 2011-27694 «Ruta Global: Análisis histórico experimental con base de datos y geovisualización espacio-temporal del comercio marítimo internacional, 1717-1850 (GlobalNet)". 


\section{INTRODUCCIÓN}

En el último tercio del siglo XVII, y sin pecar de catastrofistas, el cielo se desplomó sobre las autoridades de Filipinas y sobre las principales redes de mercaderes que operaban en las islas ${ }^{2}$. Un gran cúmulo de problemas, y el estallido de números conflictos internos, generaron grandes convulsiones sociales y económicas, hasta el punto que tanto el virrey como el inquisidor de Nueva España -siguiendo órdenes de la Cortetuvieron que arbitrar soluciones que no hipotecaran la presencia hispana en el archipiélago. Soluciones que si bien amortiguaron en parte la violencia desatada no acabaron con los trastornos exógenos en el que estaban inmersas. Los primeros fueron, en principio, fáciles de acallar. La red creada por el gobernador y capitán general Diego de Salcedo colisionó con otras más pequeñas pero que en su conjunto tenían un peso similar al del primero. La confrontación final se inició con un audaz golpe de mano como nunca antes habían conocido los habitantes de Manila 3 : el gobernador, capitán general y presidente de la Audiencia ${ }^{4}$ fue detenido por la Inquisición 5 . Arresto que, junto con al embargo de sus bienes, fue acompańado de confinamiento en una pequeña celda y, por sí el escándalo no fuera suficiente, con su muerte 'accidental'. Un proceso que seguía, como afirmó Cunningham $^{6}$, la tónica del enjuiciamiento moral del gobernador y su 'eficiencia' en el servicio público, aunque el trasfondo económico fuese el núcleo principal. Al parecer Salcedo se hallaba entre los favoritos de don Juan de Austria ${ }^{7}$ y en consecuencia con una considerable influencia en la Corte fruto tanto de sus amistades como de su valía como comandante militar y administrador. Su trabajo como gobernador en Filipinas se centró en reforzar su imagen personal, de ahí sus esfuerzos para dotar a las islas de una mayor capacidad defensiva y a la vez detener los males inherentes al archipiélago. Por eso mismo sus actuaciones se centraron en: la lucha contra la corrupción administrativa, reactivar las defensas militares de Manila, aplicar la legislación en el contrato transpacífico y limitar la influencia de la iglesia en el gobierno filipino. Esta política de reestructuración

2 Antoni Picazo. «Las redes mercantiles en el galeón de Manila», Delaware Review of Latin American Studies, Vol. 12, núm. 2, 2011.

3 En 1624 Jerónimo de Legazpi se autoproclamó gobernador general de Filipinas, pero sin la violencia del caso que nos ocupa, vid. Oswaldo Sales. "La Real Audiencia de Manila contra el gobernador general de Filipinas», Alegatos 61 (2005), pp. 419-450.

4 Mark Burkholder; D. S. Chandler. De la impotencia a la autoridad: la corona española y las audiencias en América, 1687-1808, México: FCE, 1984.

5 Archivo General de Indias -AGI-, Filipinas, 23 R8 N26. Expediente sobre los procedimientos de Diego de Salcedo, gobernador de Filipinas, en cuya virtud se le proveyó el gobierno en el año 1668 a Manuel de León, 1667-71. Sobre la Inquisición en Filipinas véase la clásica obra de José Toribio Medina. El Tribunal del Santo Oficio de la Inquisición en las islas Filipinas, Santiago de Chile: Elzenviriana, 1899.

6 Charles Cunningham. The Audiencia in the Spanish Colonies, N. Y.: Gordian Press, 1971.

7 Charles H. Cunningham. "The Inquisition in the Philippines: The Salcedo Affair", The Catholic Historical Review, Vol. 3, No. 4 (Jan., 1918), pp. 417-445. 
junto con las iniciativas de carácter personal incitó la rivalidad de tres grandes grupos de las elites filipinas: los funcionarios de la administración, los grandes mercaderes y las autoridades eclesiásticas de Manila que acabó con el arresto y prisión del gobernador.

Salcedo era un hombre pragmático donde los hubiere y sabía que sería difícil salir con vida de su cautiverio, así que ideó una sutil y elaborada venganza que partía con algo tan inocuo como era su testamento. En esa situación de vacío de poder, y a pesar de la caída de su principal competidor, los ánimos no se calmaron, ni el de los de los grandes mercaderes ni los de los oidores de la ciudad. Todo lo contrario, el deseo de acaparar los principales resortes de la administración ${ }^{8}$ precipitó una violenta lucha entre la coalición de redes que se había formado con un objetivo común: eliminar la competencia efectuada por Salcedo. El control, pues, de los centros administrativos de Manila terminó en un choque virulento, total. Una de esas redes ocupó, 'manu militari', el poder e inició las actividades de represalia contra sus antiguos socios: prisión y destierro. Era, como afirma Oswaldo Sales, el ascenso de un determinado grupo dirigente a "grupo dominante». La respuesta de la Corte y de las autoridades virreinales fue contundente. La represión se cernió sobre aquellos que habían activado y precipitado la muerte del gobernador y obligado al exilio a muchos de los oficiales reales de la ciudad.

\section{EL GOLPE CONTRA SALCEDO}

La relación que Francisco Enríquez de Losada9 envió al Consejo de Indias expuso pormenorizadamente todos y cada uno de los detalles que precipitaron la prisión del gobernador. Según este informe Salcedo empezó su mandato con un marcado desafecto a las cosas, hechuras y séquito del anterior gobernador, Sabiniano Manrique de Lara ${ }^{10}$, iniciando su juicio de residencia y desarticulando la red que lo había apoyado ${ }^{11}$. Entre sus primeras actuaciones destacan la intención de reactivar el comercio y buscar nuevos

Vid. Inmaculada Alva. La vida municipal en Manila, siglos XVI-XVII, Córdoba: Universidad, 1997.

9 AGI, Filipinas, 43 N 34. Memorial del general Francisco Enríquez de Losada pidiendo que se mande al nuevo gobernador que averigüe la injusticia de los procedimientos contra su persona por causa de José de Paternina y Juan Manuel de la Peña Bonifaz y que ocupe al suplicante y a los otros afectados en el real servicio conforme a su graduación. Francisco Enriquez de Losada tuvo una amplia participación en la consolidación comercial de Filipinas, fue embajador en Siam para activar ese trato, y el almirante al mando de las naves que consolidaron la ocupación de las islas Marianas.

10 Ana María Prieto Lucena. Filipinas durante el gobierno de Manrique de Lara, 1653-1663, Sevilla: EEHA, 1984.

11 AGI, Filipinas 9, N3, R41. Traslado de testimonio sobre la restitución del Francisco García del Fresno, capitán general de la artillería, en la plaza de general de la nao 'San José, que en 1663 salió de Acapulco hacia el puerto de Cavite, en la que venía por general de la misma Andrés de Medina Dávila. Manila, 29 de mayo de 1664. 
mercados para proveer los productos estratégicos -como el hierro-, necesarios para la construcción de naos y la conveniencia de ir a por ellos a otros puertos ${ }^{12}$. La política comercial de expansión emprendida por Salcedo fue efectiva, hasta el punto que en 1669 algunas cartas de colaboración enviadas desde otros reinos de la zona llegaron al Consejo de Indias ${ }^{13}$.

Pero ello no contuvo las rivalidades. El nueve de octubre de 1668, a las dos de la madrugada, salieron hacia palacio una serie de personajes de la elite urbana y mercantil de Manila. Entre ellos iban José Paternina de Samaniego ${ }^{14}$, religioso, miembro del Santo Oficio; los alcaldes ordinarios, el general Sebastián Rayo Doria y el capitán Nicolás de Pamplona; el capitán Gonzalo Samaniego (sobrino del citado José Paternina) junto a una serie de hombres armados: Juan Vargas Machuca, Juan de Robles, Diego Morales, Juan Morales, Diego de Palencia ${ }^{15}$ y Juan Tirado.

Este grupo accedió a las dependencias personales del gobernador y lo detuvo acusándole de varios cargos, entre ellos el de ser un hereje confabulado con los holandeses de Batavia ${ }^{16}$. De esta forma se inició un proceso que acabó con la trama de Salcedo, enfrentada a la poderosa elite mercantil, política y religiosa de Manila. Pero también abrió las puertas a violentos choques armados entre las distintas redes que optaron al poder. Como todos los gobernadores Salcedo había combinado las actividades de abastecimiento de las islas ${ }^{17} \mathrm{y}$ las personales, confundiéndose ambas pero siempre buscando dos objetivos: la consolidación y desarrollo de la presencia hispana en Filipinas ${ }^{18}$ y el beneficio económico personal a través del comercio $^{19}$-fuese lícito o ilícito-. Para ello

$\overline{12}$ AGI, Filipinas, 9 R3 N40. Carta de Diego Salcedo sobre situación a su llegada.

13 AGI, México, 43 N49. Real Decreto al presidente del Consejo de Indias.

14 AGI, Filipinas, 23 R8 N26. Carta de José de Paternina Samaniego, ministro de la Inquisición, dando cuenta de haber ejecutado la prisión del gobernador Diego de Salcedo, por motivos de fe y mala vida y por los enfrentamientos que se produjeron entre los oidores Francisco Coloma y Francisco de Montemayor. Manila, 17 de enero de 1669.

15 AGI, Filipinas, 23 R8 N26. Carta de Diego de Palencia al fiscal del Consejo de Indias, remitiéndole una carta y pidiendo remedio a los males que ocasiona el gobierno de Diego de Salcedo. Manila, 2 de junio de 1666.

16 Para el comercio el área del Pacífico, vid. Karl A. Sprengard y Roderich Ptak (Ed.). Maritime Asia. Profit, Maximisation, Ethics and Trade Structural, Wiesbaden: 1994. Para las factorías holandesas, Robert Parthesius. Dutch Ships in Tropical Waters. The developement of the Dutch East India Company (VOC) Shipping network in Asia, 1595-1660, Amsterdan: University, 2010.

17 AGI, Filipinas 9, N3, R41. Certificación del envío de dos champanes a los reinos de Siam y Camboya para la compra de trigo, hierro y otros géneros, por cuenta de la Real Hacienda, y de lo que importaron los presentes realizados a aquellos reyes, a los de Mindanao, Buhayen (Buayan) y Macasar y al virrey de Tiochu, en la China. Manila, 4 de junio de 1664.

18 AGI, Filipinas 9, N3, R41. Carta de Diego Salcedo, gobernador de las Filipinas, sobre el estado de la Real Hacienda de esas islas, 1665.

19 AGI, Filipinas, 23 R8 N26. Copia de capítulos de carta de Diego de Salcedo de 25 de junio de 1665 sobre la entrada de un patache holandés. 
había implementado una red que lo apoyaba y que, con lazos internacionales, la convertía en muy eficiente ${ }^{20}$, máxime cuando controlaba los resortes del poder político y la estratégica dinámica del galeón. Dinámica que venía, lógicamente, condicionada por la lejanía y el aislamiento del archipiélago ${ }^{21}$.

Salcedo se había rodeado de una serie de hombres con un gran peso militar y político, como el sargento Antonio López de Quirós; el capitán Luis de Matienzo 22; el general Francisco Enríquez de Losada; el almirante Juan de Altamaren; los generales Fernando de Bobadilla y Diego Cortés y una larga lista de soldados, marineros, oficiales, y comerciantes. Entre estos últimos destacaríamos las conexiones con otros puertos de la zona, por ejemplo, de Ternate, Craan Leenderiz, agente libre; Jacobo Greel, comerciante; y el mismo gobernador holandés de aquella isla ${ }^{23}$, Antony Van Voorst; los de origen portugués de Macao, Julio Gómez Payba y Nicolás Méndez; el de Goa, Antonio de Oliveira o los vínculos con el rey de Siam ${ }^{24}$ para el aprovisionamiento de artículos a través de su embajador Hacun Sinijat Sunqua. Pero el poder de Salcedo no se limitó únicamente a las islas y a sus lazos con otras áreas. En la Corte estaba relacionado con Juan del Solar, miembro del Consejo de Indias. Sus tres hermanos también poseían muy buenos anclajes en la Corte. Dos de ellos eran altos mandos militares, Alonso y Francisco Salcedo, y el tercero, Luis, era caballerizo mayor del rey y miembro del Consejo de Estado.

Frente a esta red que controló durante años el poder, pero también la dinámica económica en beneficio propio, se fue gestando una alianza momentánea de otras que

20 AGI, Filipinas, 23 R8 N26. Diferentes recaudos enviados por Diego de Salcedo en carta de 25 de junio de 1665 sobre un patache holandés que vino de la fuerza del Malayo. Manila, 1 de julio de 1665.

21 Sobre la influencia del aislamiento de Filipinas en esa dinámica de luchas intestinas véase Leslie Bauzon. "Amplia perspectiva: relaciones intercontinentales México-Filipinas» en Ernesto de la Torre (Comp.), La expansión Hispanoamericana en Asia, siglos XVI-XVII, México: FCE, 1980.

22 AGI, Filipinas, 43 N 34. Memorial de Diego de Villatoro en nombre del capitán Luis de [Pineda] Matienzo Cordero de Nevares, pidiendo que se ordene al nuevo gobernador de Filipinas que investigue la injusticia cometida contra Luis de [Pineda] Matienzo, pues se vio envuelto en un asunto de enfrentamientos que llevó al anterior gobernador, Diego Salcedo, a ser preso por el inquisidor fray José de Paternina y Samaniego, y al oidor Juan Manuel de la Peńa Bonifaz a hacerse con el gobierno militar de esas islas. Éste mandó apresar a Luis de [Pineda] Matienzo, al general Francisco Enríquez de Losada, al general Fernando de Bobadilla, a Nicolás de Sarmiento y Paredes, a Juan de Altamaren, al sargento mayor Antonio López de Quirós, a Diego Cortés y Puebla, al sargento mayor Juan de Beristain y a otros que eran sospechosos de querer reponer al gobernador en su puesto. Les declaró traidores y les desterró sin pruebas. Pide que se reponga su crédito y se le devuelvan sus bienes.

23 Para la importancia del comercio asiático dentro del desarrollo del capitalismo vid. Anthony Reid. "An 'Age of Commerce' in Southeast Asian History», Modern Asian Studies, Vol. 24, No. 1 (Feb., 1990), pp. 1-30.

24 Vid. Yoneo Ishii. The junk trade form Southeast Asia, Singapore: Insitute of Southeast Asia, 1998, especialmente el capítulo dedicado al Puerto de Ayuntthaa, en Siam. 
precipitaron el golpe de mano contra el gobernador ${ }^{25}$. Al frente de ellas encontramos a algunos de aquellos hombres que entraron en los aposentos de Salcedo y lo detuvieron en nombre de la Inquisición, sin que en México supieran nada del asunto: José de Paternina; el oidor Francisco Coloma ${ }^{26}$; Francisco Montemayor Mancilla; Manuel Peña Bonifaz; el ya citado general Sebastián Rayo Doria; el fiscal Enrique Gutiérrez de Mendoza; el maestre de campo Agustín de Zepeda; el almirante Cristóbal Velázquez; el notario Francisco Alonso Viscarra y una larga lista de soldados, comerciantes y, sobre todo, religiosos.

Estas actuaciones no fueron las únicas que se realizaron con rapidez y sigilo pues era necesario desmontar la red del gobernador antes que pudiera reaccionar. Por eso mismo se acusó a los hombres clave de Salcedo de intentar sacarlo de prisión utilizando la fuerza. La consecuencia inmediata fue la detención de Francisco Enríquez de Losada, gobernador y justicia mayor de la Alcaicería del Parián; al capitán Luis de Matienzo, hombre muy cercano a Salcedo; Juan Manuel de la Peńa; Diego Cortés; Francisco de Bobadilla; Nicolás Sarmiento; Antonio López de Quirós y el almirante Juan de Altamaren que fueron condenados a prisión y a destierro de no menos de 50 leguas de Manila.

Poco después se inició la lucha por el poder entre las redes que se habían coaligado para eliminar a Salcedo. Francisco Coloma reclamó el título de gobernador interino amparado en que era el oidor más antiguo. Sin embargo, Francisco de Montemayor se le opuso alegando mayor antigüedad. La tensión fue en aumento hasta que el fiscal Francisco Corcuera Mejía propuso una nueva solución, nombró directamente gobernador interino a Manuel de la Peńa Bonifaz que, comprando la voluntad de los soldados de la plaza de Manila con el dinero embargado a Salcedo, puso cerco al convento de jesuitas donde estaban reunidos los contrincantes anteriormente citados y los obligó a rendirse, con la promesa de no actuar contra ellos ${ }^{27}$. No obstante, y a pesar de ello, esa misma noche y a altas horas de la madrugada detuvieron a la mayoría de participantes de esas redes y los deportaron ${ }^{28}$. En el caso de Montemayor lo metieron a la fuerza en un champán y lo enviaron a 100 leguas de la capital.

25 AGI, Filipinas, 23 R8 N26. Carta de Juan [López Galván], obispo de Cebú, insinuando el desconsuelo que produce el gobierno de Diego de Salcedo. Manila, 25 de febrero de 1666.

26 AGI, Filipinas 9, N50. Carta de Diego Salcedo, gobernador de Filipinas, sobre los procedimientos de los ministros de aquella Audiencia y en particular de los de Francisco Coloma.

27 AGI, Filipinas, 23 R8 N26. Carta de la ciudad de Manila: Sebastián Rayo Doria, Diego Núñez de Guevara y Miguel Fernández Maroto, dando cuenta del mal gobierno de Diego de Salcedo hasta que fue preso por la Inquisición; de la violencia y el mal proceder del oidor Juan Manuel de la Peña Bonifaz, y cómo desterró a un castillo al oidor Francisco de Montemayor y Mansilla; del estado en que quedan las islas y de la necesidad de que se dé pronto remedio y se envíe a un gobernador con buenas calidades. Manila, 31 de diciembre de 1668.

28 AGI, Filipinas, 23 R8 N26. Carta de Francisco de Montemayor y Mansilla, oidor de la Audiencia de Manila, dando cuenta de cómo tras ser preso el gobernador Diego de Salcedo por la Inquisición, se apoderó del gobierno de las armas el oidor Juan Manuel de la Peña Bonifaz, que le desterró a un castillo en una isla, 12 de enero de [1669]. 
Mientras tanto Salcedo continuaba en prisión, enfermando lentamente aunque continuaba conservando su lucidez y su pragmatismo. Intuyendo su muerte redactó un testamento que fue su venganza a medio plazo. Nombró albaceas testamentarios nada menos que a Juan de Ortega y Montañés ${ }^{29}$, inquisidor y arzobispo de México, que más tarde ocuparía momentáneamente el cargo de virrey y si este no podía asumir el cargo por sobrecarga de trabajo designó como suplentes a Francisco Romero Calderón, oidor y fiscal de la Audiencia de México, al contador Gerardo Pando de Lagos y a Juan Miguel de Augusto y Álava, alcalde del crimen de la Audiencia de México. En sus primeras líneas no se intuyen cuáles fueron las ideas de Salcedo pues legó a la catedral de Bruselas 10.000 pesos para realizar un frontal y balaustrada; 5.000 pesos fueron destinados a una bolsa para casar doncellas. A su hermana María, soltera, que vivía en Bruselas le dejó 60.000 pesos, y a cada uno de sus hermanos, a Alonso, capitán de corazas y sargento mayor de caballería destinado en Flandes, a Francisco, coronel de caballería alemana y capitán de la guardia real y a Luis, del Consejo de Estado y caballerizo mayor de S. M. les legó 50.000 pesos a cada uno. Pero lo más importante fue que dejó un capital de 100.000 pesos a disposición de los albaceas, destinado a sufragar las obras pías que considerasen oportunas. Se trataba de una cantidad enorme y un poder decisorio sobre la misma absoluto. Y ahí radicaba la mejor de sus venganzas pues esos mismos albaceas se encargaron no solo de recuperar su memoria, sino sus bienes que habían sido embargados ${ }^{30}$ y que Peña Bonifaz había utilizado para la compra de voluntades de la guarnición de Manila. La represión contra todos los participantes en el proceso contra Salcedo, gestada en la Corte y activada desde Nueva España, fue pírrica y llegó tarde pues apenas pudo restaurar el honor de Salcedo. Los principales actores de ese golpe de fuerza fallecieron antes de que dictasen una sentencia definitiva contra ellos; los bienes y dinero de Salcedo desaparecieron y nunca pudieron recuperarse y el embargo decretado contra sus enemigos jamás se pudo practicar.

\section{EL PROCESO}

La acusación que mantuvo el Santo Oficio de Manila ${ }^{31}$ contra Salcedo fue, principalmente, que era un hereje que mantenía contactos con sus correligionarios asentados en Batavia. Diego de Salcedo, al igual que sus hermanos y hermanas, habían nacido en Bruselas, dentro de una familia castellana con destino en esa ciudad. Esto se convirtió en un argumento de peso para sus enemigos que no dudaron en afirmar que no era

29 Rodolfo Aguirre. «De las aulas al Cabildo. Familiares, amigos y patronos en el arzobispado de México, 1680-1730», Tzintzun, Revista de Estudios Históricos, 2008 (47), pp. 75-114.

30 AGI, Filipinas, 23 R8 N26. Real decreto al conde de Peńaranda remitiendo la consulta del Consejo de la Inquisición, sobre la consulta que a su vez le hizo el de Indias, sobre haber sido preso por la Inquisición el gobernador Diego de Salcedo. 16 de octubre de 1670.

31 AGI, Filipinas, 23R. Proceder de Diego Salcedo, 1677-81. 
flamenco sino un infiltrado holandés que quería ceder las islas a esa potencia. Según el inquisidor, y tornando a incidir en la completa herejía del gobernador, fue el responsable directo de la llegada de un navío holandés procedente de Taiwán ${ }^{32}$. Bajel que entró con la excusa de portar a un misionero español que había salido de China y recalando en esa isla. La acusación se amplió pues toda la ciudad sabía que había enviado a dos de sus hombres, Juan de Arguera y Ruiz de Aguayo, a Batavia para contratar. Este hecho había ocasionado la llegada a Filipinas de navíos de ese puerto con la intención de establecer un comercio regular. Las acusaciones del Cabildo secular de Manila ${ }^{33}$ contra Salcedo, "al que nadie se atrevía a contradecir», fueron muchas, entre ellas: la escasa religiosidad y ausencia de moral. Entre los ejemplos que rubricaban estas acusaciones encontramos: sus intentos de demoler la Capilla Real, su continuo entrometimiento en las elecciones canónicas, la expresión continua de frases irreverentes hacia los religiosos y la religión cristiana, o el hecho de que viviera amancebado. A ello se le sumaban las cuestiones de actividades económicas ilícitas como el contrabando y comercio ilegal con extranjeros, el desvío de fondos militares para las islas a sus negocios personales, el saqueo de la caja real, el continuo embargo de capitales a mercaderes y personas de alta consideración,...

Estas acusaciones fueron acompañadas con otras que lesionaban directamente los intereses económicos de la Real Hacienda, entre ellas el haber vendido un champán del rey a Pedro Quintero (pertenecía a su red) por solo 800 pesos cuando su valor real superaba los 2.000. Salcedo, aliado además con el tesorero José de la Vega, había mandado construir un navío de alto porte a cuenta de la caja real para posteriormente venderlo a un particular por la mitad de su precio, despachándolo seguidamente a Cantón con el piloto portugués Gómez Payba. José de la Vega tampoco quedó al margen de las represalias de sus enemigos pues fue acusado de mantener comercio con Batavia y con el reino de Banta a pesar de ser un procedimiento habitual. Recordemos que Fausto Cruzart mandó un navío comandado por Pedro de Oriosolo a Batavia para adquirir las anclas que no podían hallar en ningún otro mercado ${ }^{34}$. No obstante, la realidad que se amagaba detrás de estas imputaciones era otra diferente, pero que encontramos en la documentación. El gobernador «trató y contrató sin reparo géneros y mercaderías, procurando que los géneros más preciosos no fuesen a otras manos». Los cargos presentados incidieron mucho más en la línea económica. De forma común y ordinaria adquiría mercancías de la India ${ }^{35}$ y de China a bajo precio, con el capital de la caja real, y luego los vendía

32 Holandeses, españoles, chinos, japoneses... la situación de Taiwán la convertía en una plataforma estratégica para el comercio de toda el área. Vid. Tonio Andrade. How Taiwan became Chinese: Dutch, Spanish, and Han colonization in the seventeenth century, N. Y.: Columbia University Press, 2008.

33 AGI, Filipinas, 28 N79.

34 AGI, Filipinas, 15, R1 N10. Carta de Fausto Cruzart sobre compra de anclas en Batavia, 1693.

35 Prasannan Parthasanati. «Cotton textile Exports from the Indian Subcontinent, 1680-1790», XIV International Economic History Congress, Helsinki: 2006. 
demasiado caros. En esas acusaciones también hallamos las causas últimas de la gran enemistad de varios comerciantes. Algunos ejemplos lo clarificarán. Salcedo fue acusado de sustraer 47.000 pesos al mercader Manuel Suárez ${ }^{36}$ y embargó otros 15.000 al general Cristóbal Velásquez. Actuaciones que nos clarifican las cuestiones de fondo, la realidad de la colisión de intereses. Salcedo siempre cargó grandes cantidades de mercancías en el galeón, las más financiadas con capital de la caja real de Manila. Sobre este aspecto Diego de Palencia denunció que la cantidad podría ascender a 171.000 pesos sin contar las encomiendas que vendió a un allegado suyo, Diego de Ugarte, por tan solo 6.000 pesos y que también se destinaron a la carrera transpacífica. Las fricciones con los mercaderes no dejaron de aumentar, sobre todo al despachar el galeón a Acapulco Nuestra Señora del Socorro no de Manila sino desde Albay, a 180 leguas del puerto de Cavite para impedir que los residentes y comerciantes pudieran enviar sus géneros.

Todas estas denuncias fueron formuladas por diferentes cargos religiosos, políticos o militares, entre ellos por el general Sebastián Rayo Doria, casado con Ana Pestańo de la Cueva, hija del poderoso negociante Marcos Pestaño que, aunque lesionado por las actuaciones de Salcedo a lo largo de todo este proceso se mantuvo siempre en la sombra.

Estos hechos estaban basados en una seria de actuaciones concretas. En 1665 Salcedo envió a Java, al puerto de Carabón ${ }^{37}$, un barco comandado por Julio de Erqueza que se extravió y llegó accidentalmente a Batavia. Con permiso de las autoridades Erqueza cargó mercancías y productos estratégicos. Al año siguiente, el 15 de junio de 1666, entraba en Manila un navío holandés fletado en Batavia al mando de Nicolás Méndez, un portugués vecino de Filipinas y casado con una holandesa. Fue el momento óptimo ya que Salcedo aprovechó esa circunstancia para enviar una nave a Ternate e intentar adquirir bastimentos estratégicos para las islas. Este navío fue muy bien recibido por el gobernador Antony Van Voorst el cual percibió una gran oportunidad económica y redactó un documento de 'mínimos' para incentivar el comercio entre ambas partes ${ }^{38}$. Van Voorst envió a su representante, Jacob Greel, asentista y miembro del Consejo de Ternate, junto al mercader libre Craan Leenderiz para portar el convenio hasta Salcedo. Con ello remitió un regalo personal consistente, y he aquí la sorpresa, en una frasqueta con doce botellas de vino de Castilla, ocho de aceite y dos pares de pistolas. Nos llama

36 AGI, Filipinas, 43 N 47. Memorial de Manuel Suárez de Olivera, abogado de la Audiencia de Manila, sobre que el gobernador Diego Salcedo le obligó en 1666 a hacer un préstamo a la caja real de esas islas y cuando reclamó su devolución, se dictaminó que debía pagarlo de sus bienes Diego Salcedo, aunque luego fue absuelto de dicho pago. Pide que este dinero se le pague en México, 1675.

37 Pedro Murillo Velarde, Geographía Histórica, vol. VII, Imprenta Manuel Moya: 1752, explicó sobre la ubicación de los puertos de Java: «Daramajo, al oriente de Batavia; Carabón, al oriente de Daramajo».

38 Eric Van Veen. «Voc, strategies in the far east, 1605-1640», Bulletin of Portuguese/Japanese Studies, December 2001 (3), pp. 85-105. 
la atención que el abastecimiento de vino y aceite de España fuese mucho más ágil para los holandeses instalados en las islas del Maluco que para los espańoles de Filipinas. El documento, enviado por el gobernador de Ternate, contenía una serie de puntos básicos: el permiso para navegar libremente hasta Manila; libre albedrío para comprar y vender; no se les podría obligar a vender mercancías a bajo coste; estarían libres de derechos de descarga y a la vez podrían cargar géneros en Manila sin pagar tasas; $y$, finalmente, podrían tomar puerto en cualquier lugar del archipiélago. Junto con este documento, y los presentes, el navío aportó a Manila una serie de productos básicos: 1.750 libras de plomo, 1.250 libras de salitre, un tonel de vino y otro de aceite de Espańa, dos fardos (con veinte piezas cada uno) de telas de elefantes, 6.000 libras de trigo, 2.000 libras de estaño y 3.500 libras de hierro.

Las calificaciones fiscales contra Diego Salcedo emitidas por el tribunal inquisitorial fueron, a tenor de lo explicado, las siguientes: tenía trato con los herejes circunvecinos con su propio idioma; no se había confesado en dos ańos; a menudo se le podía ver jugando con el rosario; en un momento dado afirmó que en su tierra había una cosa muy buena, no existía la Inquisición; comentó que por el hecho de ser cristiano ya tenía la salvación asegurada, carecía de moral pues vivía amancebado con una mujer casada...

A lo largo de todo el proceso, bastante peculiar, testificaron muchos de esos representantes de la elite de Manila, la mayoría pertenecientes a las redes rivales, y muy pocos a Salcedo -a los cuales no se les tuvo en cuenta "a este testigo no se le hacen más preguntas por ser demasiado íntimo del gobernador»-. Entre los primeros hallamos la declaración de Nicolás Muñoz de Pamplona, alcalde ordinario de Manila el cual reafirmó la tesis mantenida por el tribunal inquisitorial que Salcedo tenía 'demasiado afecto a los extranjeros herejes'. Incluso el presbítero José Carrión mantuvo que María, la esposa del oidor Francisco Colón, le había comunicado los rumores que corrían por la ciudad que «Salcedo era un hereje». Incluso fue más allá al afirmar que éste mantenía relaciones con una mujer casada la cual no hacía vida marital con su esposo. El capitán Francisco de la Rua mantuvo que el gobernador cuando estaba despechado había afirmado a unos soldados que «llévese el diablo la misa». Otra evidencia era la gran estima que tenía hacia Juan de Liconte, de origen flamenco, al cual también convirtieron en sospechoso de ser un hereje holandés. Por si fuera poco y demostrado ese gran apego a los 'extranjeros' Salcedo contrató al borgonón Francisco Fumet que había llegado de Masulipatán. El presbítero Alfonso Pérez continuó con la acusación al mantener que «Salcedo y el gobernador de Batavia eran muy amigos» y el capitán Domingo Lorenzo añadió que «más que cristiano parece hereje». 


\section{LAS CONSECUENCIAS}

Durante todo un año Manuel de la Peña Bonifaz ${ }^{39}$ ocupó interinamente el cargo de gobernador de las islas, neutralizando los rivales, consolidando su poder y facilitando prebendas a aquellos que le apoyaban. Al poco tiempo el proceso contra los participantes en el golpe contra Salcedo se activó ${ }^{40}$ desde México. Cuando las diligencias contra los mismos empezaron a llegar a Manila ${ }^{41}$ Bonifaz se refugió en el convento de San Francisco, protegido por el mismo obispo y ayudado por un gran número de religiosos, poniendo a salvo sus bienes. En 1671 tornó a llegar una cédula contra el antiguo oidor, demandando su captura, requiriendo que en caso que aún estuviera en el convento de San Francisco lo sacasen de allí y lo enviasen inmediatamente a México. Incluso el virrey escribió al obispo para que facilitase la colaboración necesaria al nuevo gobernador, Manuel de León, para la captura de Bonifaz. También cabe señalar que, en muchos aspectos, Manuel de León siguió con la misma política iniciada por Salcedo. Apenas llegar a su gobernación León recibió a la embajada del rey de Siam y continuó con las expectativas de negocio ${ }^{42}$ y aún de ayuda a dicho reino consolidadas por Salcedo. Negocios que no podía ser truncados, de ahí que tras sufrir diversos ataques del reino de Ternate y de los holandeses el rey de Siam demandó la ayuda de los españoles, enviándole una pequeña dotación formada por un cabo y catorce soldados con la finalidad de contener la invasión ${ }^{43}$.

Mientras tanto había empezado el proceso para restituir el honor y las propiedades de Salcedo y de sus allegados. Pocos años después, en 1674, Manuel de León informó al virrey que Bonifaz había muerto y que no hallaba sus bienes «...por ninguna

39 AGI, Filipinas, 10, R1, N3. Carta de Manuel de León, gobernador de Filipinas, informando del proceso llevado a cabo contra Juan Manuel de la Peńa Bonifaz, oidor, por querella de Francisco de Mansilla, oidor, y de otras causas pendientes contra este oidor; de la llegada de una embajada del reino de Siam y de la respuesta que le dio; los efectos ocasionados por el ganado mayor que formó en la Pampanga Diego Salcedo, gobernador que fue de Filipinas, 1670. AGI, Filipinas, 10, R 1, N 21. Testimonio de autos seguidos contra Juan Manuel de la Peńa Bonifaz, oidor que tomó el gobierno de las islas tras ser apresado Diego Salcedo por causa grave de fe. Manila, 11 de junio de 1670.

40 AGI, Filipinas, 23 R8 N26. Acuerdo del Consejo sobre hacer consulta e informar sobre las noticias que se han tenido de la prisión de Diego de Salcedo. Consejo, 7 de agosto de 1670. AGI, Filipinas, 23 R8 N26. Decreto del Consejo sobre unas cartas acerca de la prisión de Diego de Salcedo que fueron entregadas a Diego Sarmiento Valladares, inquisidor general. Consejo, 8 de agosto de 1670.

41 AGI, Filipinas, 10, R 1, N 21. Copia de carta de Manuel de León, de 4 de julio de 1672 contestando a una carta del tribunal de la Inquisición sobre el castigo dado a los ministros del Santo Oficio por el encarcelamiento que dieron a Diego Salcedo. Expone los excesos del padre Paternina, de Juan de Montemayor y Mansilla, tesorero general de la Cruzada, de Francisco de Vizcarra, alguacil mayor, del sargento Juan Muñoz de Gadea, guardia mayor, del almirante José de Chaves, alguacil mayor que sustituyó a Vizcarra; todos miembros del tribunal de la Inquisición.

42 AGI, Filipinas, 10 R1 N7. Carta de Manuel de León sobre embajada de Siam.

43 AGI, Filipinas, 331 L7 f. 77v.-78r. Aprobación de la ayuda al rey de Siam. 
parte...». Aquel mismo ańo León recibió una misiva en la que ordenaba que todos los religiosos ${ }^{44}$ que habían ayudado a Bonifaz fuesen sacados de Manila y enviados a lugares remotos y apartados de las islas. En 1678 Juan de Vargas accedió al cargo de capitán general de las islas y al poco tiempo recibió la sentencia del juicio que condenaba a prisión a todos los que, de una forma u otra, habían participado en el golpe contra Salcedo. La mayoría de condenados ya habían muerto y sus bienes, que habían sido embargados, fueron ocultados por sus aliados.

\section{CONCLUSIONES}

El análisis de las redes, especialmente de las complejas ${ }^{45}$, ha sufrido en esta última década un salto cuantitativo y cualitativo sumamente importante. Los estudios sobre las mismas se han multiplicado muchísimo, y los programas informáticos que permiten su visualización han evolucionado de una forma totalmente asombrosa. Las novedades que presentan algunos de ellos evidencian una proliferación inusitada de posibilidades analíticas ${ }^{46}$ totalmente novedosas. Así, por ejemplo, la utilización de los Sistemas de Información Geográfica -SIG- espacio-temporales a la Historia y al estudio de redes ha sido uno de los máximos exponentes de este cambio sustancial vivido en nuestra disciplina y que, a la postre, augura un futuro tremendamente prometedor. En nuestro caso hemos aplicado el programa Tulip, desarrollado por la Univesidad de Burdeos, para penetrar en la red creada por Salcedo y en la configuración de la de sus rivales. Ello nos ha llevado a una serie de conclusiones generales.

La red egocentrada sería la creada por una persona, que ostenta la máxima centralidad, con su entorno más inmediato fijándose una estructura relacional con otros

44 AGI, Filipinas, 10, R 1, N 21 Carta del Tribunal del Santo Oficio de México, de 14 de enero de 1672 contestando a una carta de Manuel de León de 15 de junio de 1671 sobre la actuación de fray José de Paternina [Samaniego] y el castigo dado a los ministros de ese tribunal que participaron en el encarcelamiento de Diego de Salcedo.

45 Phillip Anderson. "Complexity Theory and Organization Science», Organization Science, vol. 10, n. 3, (1999), pp. 216-232 expone sintéticamente la definición de 'complejidad' de varios autores «Simon defined a complex system as one made up of a large number of parts that have many interactions (Simon 1996). Thompson (1967, p. 6) described a complex organization as a set of interdependent parts, which together make up a whole that is interdependent with some larger environment", p. 216. En cambio para W. Brian Arthur. "Complexity and the Economy», Science, (1999), Vol. 284, n. 5411, pp. 107-109 la complejidad no sería otra cosa que un «sistema adaptativo».

46 G. Lenski. Poder y privilegio: teoría de la estratificación social, Paidós, 1993 y Max Weber. Sociología del Poder: los tipos de dominación, Madrid: Alianza, 2007 investigaron en su día, y por separado, las distintas estrategias diseńadas para alcanzar el poder, consolidarlo o ampliarlo y la importancia del prestigio en la sociedad del Antiguo Régimen. No obstante, cabría diferenciar entre 'poder' e 'influencia'. En ese aspecto vid. D, Willer, M. Lovaglia y B. Markovsky. «Power and Influence: A Theoretical Bridge», Social Forces, Vol. 76, No. 2 (Dec., 1997), pp. 571-603. 
individuos con los que interactúa de diferente forma y actitud. En el caso que nos ocupa las que se gestaron en las Filipinas hispánicas siempre persiguieron objetivos concretos, fuesen estos legales o ilegales. No obstante, su eficiencia estuvo siempre vinculada a dos factores fundamentales: su complejidad y el número de lazos. Referente a la primera de ellas. Y no fue el caso de la creada por Salcedo que era extremadamente centralizada. De ahí que al caer el nódulo principal toda la red colapsara. En cambio en el aspecto relacional y de lazos si que hallamos una cierta eficiencia pues en apenas dos saltos el núcleo se vincula directamente con el monarca y en solo tres saltos tenían la misma posibilidad los agentes periféricos que la formaban. Igualmente cabría destacar que la red de Salcedo abarcaba varias áreas geográficas y agentes extranjeros de la zona Asia-Pacífico. Así, no solo se ubicó y desarrolló su actividad en Filipinas, sino que la extendió a Siam, Ternate, China para pasar a Nueva España y acabar en la misma Corte.

Otra de las conclusiones a las que llegamos tras la visualización de las redes es la dinámica de choques. Efectivamente, el poder que detenta una red siempre es deseado por sus rivales. Cada una de ellas mantiene un peso gravitatorio específico el cual no provoca cambios en la estructura del poder mientras no se altere. El choque solo se produce cuando los distintos pesos preexistentes mutan y adquieren más complejidad. Solo es entonces cuando se producen los cambios. Esto lo podemos percibir claramente en las redes de Bonifaz, Coloma y Paternina que mientras estuvieron aisladas unas de otras y enfrentadas no lograron desbancar a Salcedo. Solo, y únicamente, cuando pasaron de la simplicidad a la complejidad, de la centralidad mononuclear a la descentralización polinuclear la red cobró una eficacia superior a la de Salcedo y pudo suprimirla. Y esta misma red cayó cuando Bonifaz desmanteló por completo la coalición, aniquilando a sus compañeros de viaje y asumiendo el poder en solitario. 


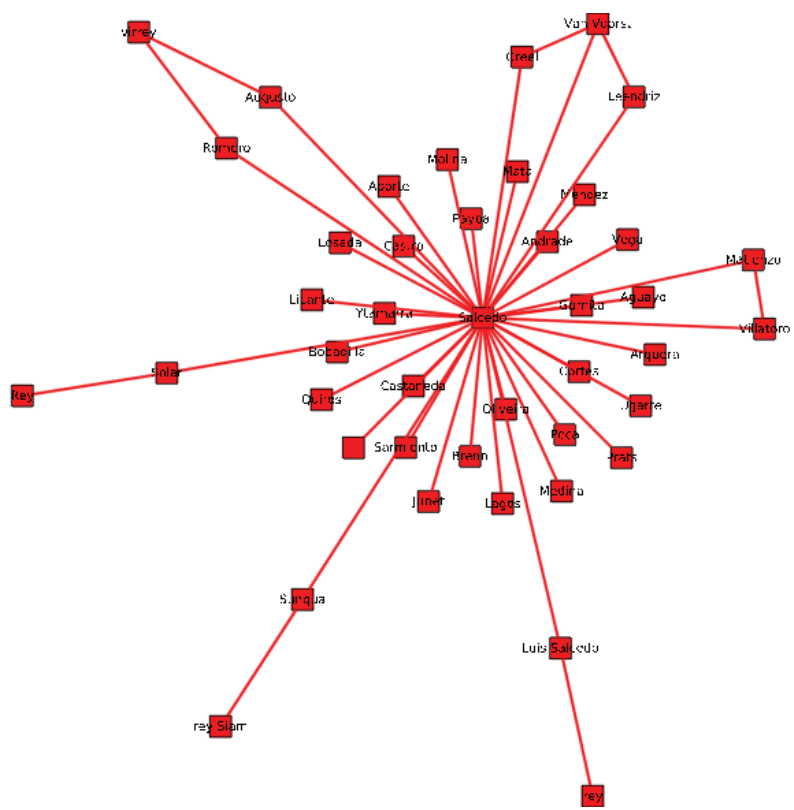

GRÁFICA 1: Visualización de la red egocentrada de Salcedo.

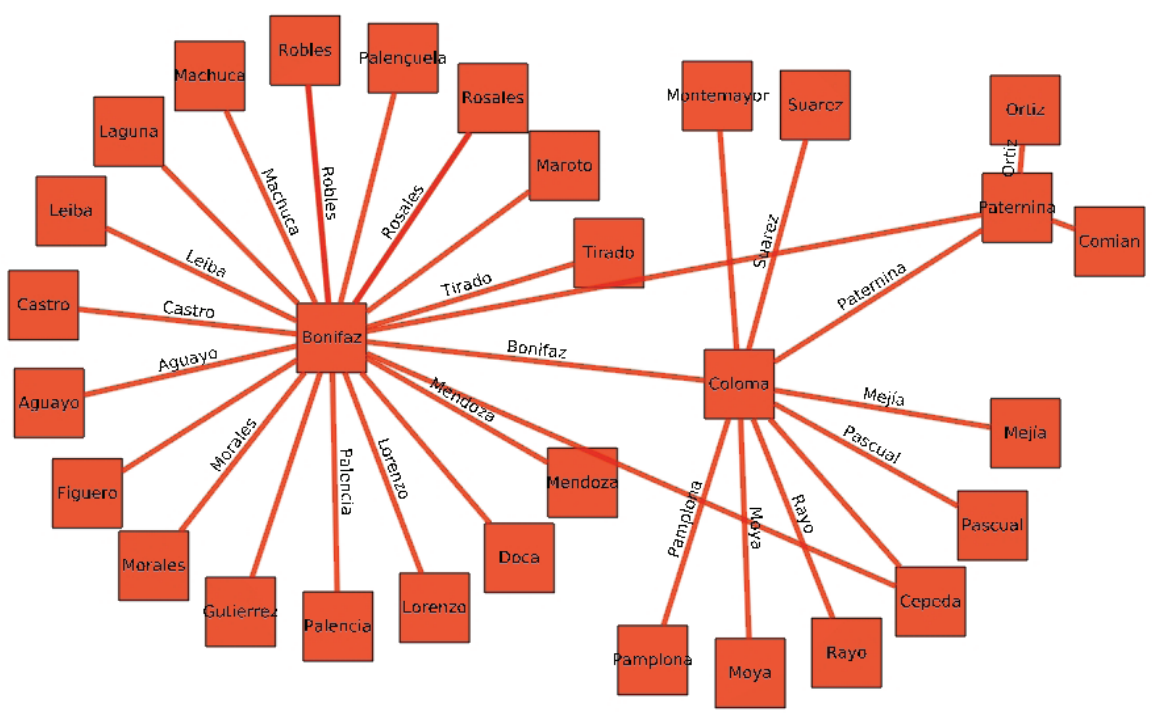

GRAFICA 2: Visualización de la red egocentrada de Bonifaz y Coloma. 